\title{
ANÁLISIS DE LOS ASPECTOS BIOÉTICOS EN LOS PROGRAMAS DE DONACIÓN EN ASISTOLIA CONTROLADA
}

\begin{abstract}
José Manuel Álvarez Avello', José Antonio Santos²
Resumen: El trasplante de órganos sólidos constituye el tratamiento de un gran número de enfermedades en fase terminal, mejora globalmente la supervivencia y la calidad de vida de los pacientes sometidos a este tipo de intervención y es considerado como un beneficioso progreso de la medicina para el conjunto de la sociedad. En las últimas décadas, y debido al estancamiento en la cantidad de donaciones y al aumento progresivo de las listas de espera, se han desarrollado diferentes acciones con el objetivo de ampliar el número potencial de donantes, reconsiderando nuevamente aquellos procedentes de parada cardiocirculatoria (donantes en asistolia). El objetivo de este trabajo consiste en reflexionar sobre la legitimidad de compaginar en un mismo proceso dos complejas decisiones éticas: la retirada de las técnicas de soporte vital (RTSV) y limitación del esfuerzo terapéutico (LET), y la posibilidad de considerar a estos pacientes como donantes de órganos. Con este propósito, analizaremos los problemas éticos que se plantean a cada paso en la toma de decisión y en las actuaciones en los programas en asistolia controlada, según el criterio de donantes tipo III adoptado en la conferencia de Maastricht de 1995, como fundamento para establecer un juicio ético de todo el proceso.
\end{abstract}

Palabras clave: paro cardíaco, eutanasia, futilidad médica, sistemas de soporte vital, trasplante

\section{Analysis of bioethical issues related to organ donation in controlled asystole programs}

\begin{abstract}
Solid organs trasplant constitutes a treatment for many diseases in terminal phase. Patients subjected to this type of intervention enhance survival and quality of life in general and it is considered a beneficial progress in medicine for society. In the last decades and due to the stagnation of donations and the progressive increase of waiting lists, some actions have been developed with the goal to widen the potential number of donors, reconsidering again those coming from cardiovascular arrest (asystole donors). The aim of this article consists in reflecting on the legitimacy of combining in the same process two complex ethical decisions: the withdrawal of life support techniques (WLST) and the limitation of therapeutic effort (LTE), and the possibility of considering these patients as organ donors. With this purpose, we will analyze the ethical problems involved in each step in decision making and on the actions taken by controlled asystole programs, according to the criteria of type III donors of Masstricht conference, 1995, as base to establish an ethical judgment for the process.
\end{abstract}

Key words: cardiac arrest, euthanasia, medical futility, life support systems, trasplant

\section{Análise dos aspectos bioéticos nos programas de doaçáo em assistolia controlada}

Resumo: O transplante de órgãos sólidos constitui o tratamento de um grande número de enfermidades em fase terminal, melhora globalmente a sobrevivência e a qualidade de vida dos pacientes submetidos a este tipo de intervenção e é considerado como um beneficente progresso da medicina para o conjunto da sociedade. Nas últimas décadas, e devido ao estancamento na quantidade de doações e ao aumento progressivo das listas de espera, desenvolveram-se diferentes açóes com o objetivo de ampliar o número potencial de doadores, reconsiderando novamente aqueles procedentes de parada cardiocirculatória (doadores em assistolia). O objetivo deste trabalho consiste em refletir sobre a legitimidade de compaginar num mesmo processo duas complexas decisóes éticas: a retirada das técnicas de suporte vital (RTSV) e limitação do esforço terapêutico (LET), e a possibilidade de considerar estes pacientes como doadores de órgãos. Com este propósito, analisaremos os problemas éticos que se apresentam a cada passo na tomada de decisão e nas atuações nos programas em assistolia controlada, segundo o critério de doadores tipo III adotado na conferência de Maastricht de 1995, como fundamento para estabelecer um juízo ético de todo o processo.

Palavras-chave: parada cardíaca, eutanásia, futilidade médica, sistemas de suporte vital, transplante

\footnotetext{
${ }^{1}$ Hospital Universitario Puerta de Hierro, Madrid, España.

${ }^{2}$ Cátedra de Bioética y Bioderecho de la Universidad Rey Juan Carlos, Madrid, Espańa

Correspondencia: joseantonio.santos@urjc.es
} 


\section{Introducción}

El trasplante de órganos sólidos supone, desde hace más de cuarenta años, una alternativa válida y eficaz en el tratamiento de un gran número de enfermedades orgánicas en fase terminal(1), mejora globalmente la supervivencia y la calidad de vida de los pacientes sometidos a este tipo de intervención, y es considerado como un beneficioso progreso de la medicina para el conjunto de la sociedad. El número de trasplantes realizados al año, en todo el mundo, se estima en torno a 100.000(2). Aunque el desarrollo inicial de los primeros trasplantes se realizó a partir de donantes que habían cesado en sus funciones cardiorrespiratorias, el principal avance de estas técnicas estuvo determinado por la definición, aceptación y generalización de los criterios de muerte encefálica a fines de los años sesenta del siglo pasado(3). Sin embargo, en las últimas décadas, y debido al estancamiento en la cantidad de donaciones y al aumento progresivo de las listas de espera, se han venido desarrollado diferentes acciones, con el objetivo de ampliar el número potencial de donantes, reconsiderándose nuevamente aquellos procedentes de la parada de las funciones cardiocirculatorias (donantes en asistolia). Se estima que este tipo de donaciones podría aumentar el número potencial de donantes hasta en un 25 $30 \%(4,5)$.

La donación en asistolia considera, una vez determinado el cese de la función circulatoria, la posibilidad del explante de los órganos. La recuperación de este tipo de donación se produjo en distintos países a principios de los años ochenta del siglo pasado. Desde entonces se han diseñado, progresivamente, protocolos que permiten optimizar la preservación de los órganos, siendo técnicamente posible en la actualidad la realización de trasplantes renales, hepáticos, pancreáticos, pulmonares e incluso, más recientemente, cardíacos(6).

La clasificación de Maastricht, ampliamente utilizada en Europa para aunar estos modos de donación y recientemente modificada en $\operatorname{Madrid}(7)$, define las categorías en las que podemos dividir este tipo de donantes. Se consideran, en líneas generales, dos grandes grupos. Aquellos en los que la parada cardiorrespiratoria se produce de forma imprevista y no controlada, habitualmente sometidos a maniobras de resucitación infructuosas (tipos I y II), y aquellos en los que el fallecimiento se produce en un contexto de control y vigilancia médica. En este grupo de donantes controlados se diferencian, a su vez, aquellos en los que la parada cardiocirculatoria se produce después de aplicar procedimientos de limitación del tratamiento de soporte vital (LTSV) (tipo III) y los producidos en situación previa de muerte encefálica (tipo IV).

En 1993, la publicación del protocolo sobre donación de órganos, después de la retirada controlada del soporte vital de Pittsburg(8), encendió la polémica científica y el debate bioético sobre estas formas de actuación. La discusión sobre el tiempo de espera desde el cese de las funciones cardiovasculares a la extracción de órganos, el respeto a la Dead Donor Rule(9), la manipulación ante-mortem del donante o el conflicto de intereses entre el donante y receptor afloraron en la literatura internacional a medida que se iban implementando estos protocolos en los distintos países. En Estados Unidos, la conferencia de consenso sobre donación en situación de "muerte cardiaca”, celebrada en Filadelfia en 2005(10), concluyó con la unificación de criterios, la aprobación y la potenciación de estas formas de donación, considerándolas como no contrarias a la práctica ética médica. En Europa, diez de los países miembros de la Unión Europea presentan programas de donación en asistolia. En Francia y España la mayor parte de esta actividad se realiza con donantes no controlados; en cambio, Reino Unido, Bélgica y Holanda promedian una tasa mayor de donantes controlados, países en los que esta actividad se asocia con una significativa disminución de la tasa de donación en muerte encefálica, hecho al que no se le reconoce una justificación clara(11).

\section{Método}

En este trabajo se analizarán de forma sistematizada los problemas éticos que plantean los programas en asistolia controlada, teniendo en cuenta el criterio de donantes tipo III adoptado en la conferencia de Maastricht de 1995, según el orden cronológico en la toma de decisión y las actuaciones que estos programas precisan. Para ello se describe de forma sucinta su fundamentación y la forma en la que se llevan a cabo. 
En primer lugar, es necesario plantear un cambio de nomenclatura que haga referencia no a la parada de la función del corazón (asistolia), sino a la pérdida de su función circulatoria, es decir, a la capacidad que tiene el corazón de desarrollar presión arterial efectiva para generar flujo sanguíneo arterial a los distintos órganos y tejidos independientemente de que exista o no actividad eléctrica cardiaca. Los términos propuestos, de esta forma, comprenderían su denominación como "Donación tras Muerte Constatada por Criterios Circulatorios" o el de "Donación tras Muerte Circulatoria", aunque, en sentido estrictamente clínico, también se podría catalogar dicha situación como de actividad eléctrica sin pulso.

Los donantes tipo III de Maastricht presentan como dato esencialmente característico la asociación de la donación por criterios de muerte circulatoria con la LTSV o la retirada de las técnicas de soporte vital (RTSV) del futuro donante, realizado bajo una estrecha vigilancia, de forma que permita disminuir el tiempo de isquemia caliente, en el que la lesión y afectación de los órganos es mayor. En cuanto a la LTSV, se considera que esta decisión debe tomarse por el equipo médico responsable del paciente, de forma independiente a la estructura de coordinación de trasplantes. Una vez que la familia haya aceptado la situación y consentido la limitación del esfuerzo terapéutico, se procedería a la petición de permiso para la donación de órganos y tejidos en caso de que pudieran ser válidos para el trasplante. En este sentido, los candidatos a ser donantes controlados, tras la muerte cardiaca, serían aquellos pacientes en los que se decide la RTSV. Habitualmente, se trata de lesiones neurológicas irreversibles, enfermedades neuromusculares avanzadas, lesiones espinales altas y enfermedades respiratorias terminales, que se pueden realizar en el quirófano o en la UCI según el protocolo que se acuerde en cada centro. En todo caso, la analgesia y sedación se deben suministrar en las dosis necesarias para evitar el sufrimiento del paciente.

Estos protocolos contemplan la posibilidad de realizar medidas de preparación antes del fallecimiento, con el fin de facilitar una mejor preservación de los órganos una vez que se produzca. Tales medidas consistirían en la administración de heparina, el uso de fármacos vasodilatadores o la disección y canulación de la arteria y vena femoral previas a la RTSV. Desde el momento de la RTSV, se procede a la monitorización y registro continuo hasta la pérdida de la función circulatoria del donante. Esta fase agónica no debería ser prolongada para poder aceptar la validez de los órganos. En líneas generales, se acepta que si transcurridas dos horas no se produce la asistolia, el paciente regresa a la UCI donde es atendido hasta su fallecimiento. Para intentar pronosticar que este tiempo sea inferior a lo deseado, se han realizado distintas escalas que, analizando la situación clínica y el soporte requerido por el donante, pudieran predecir las posibilidades de muerte en menos de 120 minutos.

Una vez producido el cese de la función circulatoria se procede a la certificación de la muerte del paciente. La muerte cardiaca se certifica tras un periodo de observación de cinco minutos tras el cese de la circulación. Esta certificación se la realiza de forma independiente del sistema de coordinación de trasplantes. Tras certificar la muerte del paciente, no se deben reanudar maniobras que puedan inadvertidamente recuperar la circulación o perfusión cerebral, especialmente si se emplean dispositivos de circulación extracorpórea para facilitar la preservación de los órganos. Posteriormente se procede a la extracción de los órganos y a su implante en los pacientes receptores.

\section{Análisis de los aspectos éticos}

El contexto clínico donde se desarrolla el programa de donación en asistolia controlada nos permite analizar, de forma más detallada, los problemas éticos que de él se derivan. De esta forma, se pueden reconocer varias cuestiones que afectan al análisis ético de estos modelos de donación.

\section{LET y donación multiorgánica}

En primer lugar, y como base de todo el debate que este tipo de donación suscita, debemos preguntarnos si está éticamente justificada la asociación de la limitación del esfuerzo terapéutico (LET) con la donación multiorgánica. ¿Se trata de un aspecto a fomentar y potenciar en el cuidado de las atenciones al final de la vida o, por el contrario, constituye de un conflicto de intereses irreconciliable que debe ser a priori desestimado? 
La LET se puede considerar como el acto médico de retirar o no iniciar las medidas terapéuticas, cuando el profesional sanitario considera que, en la situación concreta del paciente, son clínicamente ineficaces para mejorar el pronóstico, los síntomas o las enfermedades intercurrentes, o porque previsiblemente producen perjuicios personales, familiares, económicos o sociales desproporcionados al bien que se quiere conseguir(12). Constituye así una de las decisiones de mayor consideración bioética en la medicina intensiva, al ser con frecuencia objeto de importantes incertidumbres y divergencias que afectan al personal sanitario y al entorno familiar del paciente. Una cuestión esencial en la LET es la proporcionalidad del tratamiento en relación a la futilidad. El juicio de desproporcionalidad se genera cuando los resultados o fines perseguidos se entienden inútiles en comparación con los medios dispuestos. Los juicios sobre la futilidad podrán ser más o menos absolutos, en la medida en que se pueda objetivar la no consecución del objetivo fisiológico deseado. En la mayoría de los casos, existe gran variabilidad en la consideración de la futilidad, por lo que el margen de ambigüedad puede ser alto, dado que las decisiones clínicas no pueden tener un carácter de certeza sino probabilístico.

Estas ciertas dificultades de los procesos de LET se agudizan si, en la toma de decisiones, se le ańade una nueva incógnita: ¿este paciente podría ser donante de órganos una vez se considere y acepte la LET? Esta pregunta sobre la validez de los órganos se realiza, a diferencia de los otros modos de donación, sobre el paciente vivo. En estos casos podría entrar en conflicto el principio de prudencia, necesario para la toma de decisiones sobre la LET, con el principio de utilidad, que reclama la premura suficiente para permitir la ausencia de deterioro de los órganos vitales(13). En la prácti$\mathrm{ca}$, ¿no podrían precipitarse este tipo de decisiones al existir esta posibilidad?

En definitiva, el proceso de donación debe estar presente en los proceso del final de la vida en las UCIs. Sin embargo, el posible beneficio que pueda aportar la donación a un futuro receptor no debe ser excusa o motivo para condicionar una sobreestimación de los posibles donantes, sino que debe prevalecer el principio de responsabilidad a la hora de tomar decisiones, puesto en relación con los de integridad y autonomía del paciente.

2. Autonomía del paciente en estos procedimientos

Resulta innegable que los pacientes, en situación clínica de extrema gravedad, se encuentran en situación de limitación o invalidación de su autonomía personal. Factores como la gravedad de la enfermedad causal, los fármacos sedantes y las medidas de soporte vital hacen que los pacientes tengan disminuidas o abolidas sus funciones cognitivas y su capacidad de comunicación; lo que determina, en la práctica, su incapacidad para decidir sobre su proceso patológico. Estos hechos no deberían condicionar la realización de actos médicos o tratamientos invasivos a los que el paciente hubiera manifestado, en plenitud de sus capacidades, un rechazo inequívoco. Del mismo modo, deberían respetarse aquellas peticiones realizadas previamente a la enfermedad, entre ellas, su disposición a la donación de órganos.

El programa de donación en asistolia controlada tipo III establece en sus protocolos que cualquier paciente en situación de LTSV y que reúna los criterios de donante potencial debería tener la posibilidad de donar sus órganos, de esta forma estaríamos respetando su voluntad y autonomía(6:95). Analicemos, según estas premisas, algunos aspectos del principio de autonomía. Para Beauchamps y Childress(14:57), se consideran autónomas aquellas decisiones que respondan a una intención, realizadas con conocimiento, lo que lleva implícito la capacidad de comprensión, razonamiento y reflexión, y que carezcan de influencias externas que pretendan controlar la elección. En el ejercicio de la medicina se establece, de esta forma, el deber de respetar la autonomía de la voluntad de los pacientes. Sin embargo, estaríamos reduciendo su significado al considerar ésta como el único valor de legitimidad ética en la práctica clínica. Un verdadero respeto a la autonomía del paciente debe encuadrarse en una práctica médica sensible a los valores constitutivos del ser humano, fundamentados, de acuerdo con Pellegrino y Thomasma, en el principio de beneficencia, la dignidad de la persona, la humanización de la medicina y el modelo de confianza de la relación médico-paciente. Esto se traduce en un camino intermedio entre el paternalismo y la 
autonomía que conduzca a una beneficencia fiduciaria o en confianza (beneficence-in-trust), que tenga en cuenta tres axiomas: en primer lugar, la esencia de una verdadera profesión reside en su promesa pública de actuar con base en la naturaleza de su función en sociedad; en segundo lugar, un alto grado de altruismo que suscite el interés de aquellos a quienes sirve, y, en tercer lugar, que las obligaciones de los profesionales sanitarios se basen en la naturaleza de la enfermedad, en la fidelidad a su promesa de ayudar y en el poder para ayudar que reside en el conocimiento y habilidad profesionales(15).

Es responsabilidad del profesional una información veraz que estimule la reflexión y la decisión propia del paciente, estableciendo, a través de una verdadera relación personal, la ayuda, asesoramiento y soporte que permita, según las preferencias de este, la toma de decisiones relacionadas con su enfermedad. Se debe evitar, por tanto, actitudes paternalistas o informaciones sesgadas y falseadoras para lograr un objetivo ajeno al paciente. Una de las formulaciones del imperativo categórico kantiano señala: "Obra de tal modo que se use la humanidad, tanto en tu persona como en la persona de cualquier otro, siempre como un fin al mismo tiempo y nunca solamente como un medio" (16:52).

¿Cómo podemos encuadrar este respeto a la autonomía personal con los protocolos de donación en asistolia controlada? En el caso de la muerte encefálica este problema resulta menor, puesto que el paciente es ya cadáver a la hora de la aceptación de la donación por parte de sus familiares, de acuerdo con su biografía y deseos previos. En la donación en asistolia no controlada este problema se acentúa, al realizarse medidas no aceptadas expresamente por el paciente, pero en estos casos el diagnóstico de muerte clínica por criterios cardiovasculares (maniobras de resucitación no satisfactorias) también se ha producido y el sujeto es considerado como fallecido una vez que se plantea la donación. Sin embargo, en los programas de asistolia controlada estas decisiones se toman mientras el paciente está en situación terminal, pero aún con vida. Por este motivo, tanto el médico como sus representantes legales deben ser especialmente sensibles al beneficio del paciente, hecho que se sustenta además en lo establecido en el Convenio de Oviedo, que señala: “Solo podrá efectuarse una intervención a una persona que no tenga capacidad para expresar su consentimiento cuando redunde en su beneficio directo" (17).

Para considerar necesaria esta relación entre autonomía y beneficencia debemos analizar también si los cauces de comunicación producidos en estas situaciones son suficientes para garantizar un conocimiento pleno y una adecuada capacidad de reflexión sobre el entorno, que permitan una actuación centrada en el beneficio directo del paciente. En este sentido, ¿se produce realmente una información apropiada sobre este tipo de donación y sus características? ¿Ha existido información suficiente en los medios de comunicación? ¿Bastaría con la información realizada en el momento de solicitar los órganos? En la actualidad, la información sobre este procedimiento se realiza inmediatamente después de la decisión y aceptación de la RTSV; situación que, debido al desconcierto y sufrimiento que suele acompañar este momento, afecta a la capacidad de entendimiento y reflexión de los familiares, existiendo una vulnerabilidad de la autonomía de su entorno que requiere de medidas que protejan de una posible intromisión en la libertad de decisión. Por ello, sería imprescindible realizar, como condición previa a la instauración de este tipo de donaciones, un debate social claro y veraz que explique a la opinión pública las características propias y diferenciadoras respecto de otras formas de donación.

\section{Manipulación ante-mortem del donante}

Para evitar el deterioro que se produce durante el tiempo de isquemia caliente, los protocolos de donación en asistolia controlada tienen prevista la utilización de fármacos, generalmente anticoagulantes o vasodilatadores, que disminuyan el riesgo de trombosis y permitan un mejor mantenimiento del flujo sanguíneo orgánico. De igual forma, también contemplan la posibilidad de realizar, antes de la RTSV, la canulación de los vasos femorales, con el objetivo de no demorar el inicio de la perfusión de las soluciones de preservación una vez certificado el fallecimiento. El problema se produce al intentar justificar la realización de medidas invasivas o medicamentosas no terapéuticas sobre el donante; es decir, medidas que por sí mismas no resulten beneficiosas e incluso pu- 
dieran generar perjuicios (sangrado o hipotensión arterial) en el donante, antes de su fallecimiento, en favor del futuro receptor.

Desde una perspectiva ética consecuencialista(18) $\mathrm{y}$ atendiendo al principio de utilidad, dichas actuaciones resultarían plenamente justificadas, al estar encaminadas a conseguir un beneficio para un mayor número de personas, hecho que no podría realizarse sin el empleo de estos procedimientos(19). Además, sobre un análisis somero de los principios de autonomía, beneficencia y no maleficencia, podríamos justificar su uso, al considerar que la preservación y viabilidad de los órganos favorece la voluntad del paciente de ser donante y por lo tanto su mejor interés (beneficencia), facilitando a su vez las maniobras de extracción de órganos y la agresividad quirúrgica del explante (no maleficencia) (6:194).

Otras formas de justificación ética las podemos encontrar en el principio del doble efecto. DuBois plantea de esta forma que el empleo de heparina no es en sí mismo moralmente malo, porque su fin último es la preservación de un órgano que pueda luego salvar una vida y el efecto secundario del sangrado no es deseado(20). En cambio, Childress rechaza esta argumentación, al considerar que solo sería válida su aplicación si la finalidad del efecto deseado tuviera su aplicación en el propio donante y no en un tercero, como ocurre en los programas de donación en asistolia controlada(21). Para Steinberg, podría resolverse el problema si aceptamos que nos encontramos ante un acto de altruismo por parte del paciente o sus familiares, en el cual el beneficio del paciente es libremente cedido, dentro de unos límites, en pro de un ejercicio solidario para con el receptor(22). En este caso, aunque se vulneren los principios de beneficencia y no maleficencia, la disposición generosa que el paciente hace de su propio cuerpo para un bien superior podría fundamentar la realización del acto. Sin embargo, no acierta a establecer estos límites, ni tampoco considera, como analizaremos a continuación, la mediación en este proceso de un acto médico. Lo que sí parece razonable es que, si acaso, la opción de donación altruista debería tomarse en consideración cuando se produce de forma completamente autónoma y personal. Por el contrario, las dificultades ya analizadas sobre las circunstancias en las que se plantea invitan más a una mera instrumentalización que a un acto de solidaridad.

No podemos olvidar que las medidas realizadas para la preservación de los órganos se realizan en el contexto de un acto médico, de un paciente en vida, en situación de máxima debilidad y dependencia, en los que se ha establecido la imposibilidad de lograr el objetivo de su curación, pero donde deben mantenerse todas las medidas relacionadas con sus cuidados, sobre la base de la dignidad propia de una biografía única e irrepetible que llega a su fin. Por este motivo, es preciso fundamentar este acto clínico en "el bien del paciente como elemento objetivo y de finalidad" (23:285), garantizando así el respeto a la dignidad en el final de la vida. Vale recordar nuevamente el imperativo kantiano según el cual la acción debe realizarse de tal modo que la otra persona sea el fin y no meramente el instrumento de la acción, que encuentra en la norma personalista de la acción su expresión en el campo de la bioética; advirtiéndose así que, la condición de fin que posee la persona, no solo es un descubrimiento sobre su ser personal sino también sobre el deber ser que surge de ella(24:66). Es por este motivo por lo que una decisión aparentemente autónoma, realizada por el paciente o por terceros, que se oponga al bien e interés del propio paciente, debería llevar al médico a tratar de evitarla intentando, en la medida de lo posible, la restauración del bien del paciente que le permita recuperar su verdadera $\operatorname{dignidad}(25)$.

Podemos considerar que la manipulación anterior al fallecimiento de los pacientes, sometidos a protocolos de donación en asistolia controlada, constituye un importante inconveniente ético y debe considerarse como una forma de instrumentalización contraria a su dignidad. Se deberían estudiar e investigar otras formas, métodos o procedimientos que, respetando la naturaleza propia del acto médico, permitan un aprovechamiento óptimo de los órganos.

4. Cuidados al final de la vida del paciente crítico y riesgo de aceleración de la muerte

Una vez indicada la decisión de la RTSV, el objetivo clínico se centra en favorecer todas aquellas medidas que puedan mejorar el confort y 
los cuidados del paciente hasta su fallecimiento. La reducción de las técnicas de monitorización, la supresión de medidas de control analítico, la creación de un ambiente sereno, el empleo de fármacos analgésicos e hipnóticos que permitan un estado de placidez, el acompañamiento familiar o la atención religiosa, si es requerida, junto con la información y el soporte a los acompañantes del paciente, constituyen aspectos progresivamente más valorados y apreciados de satisfacción y calidad asistencial de las UCIs(26). Todas estas medidas están encaminadas a desarrollar y hacer presente el denominado "principio de humanidad", que debe prevalecer en toda atención terminal y que acierta a dar respuesta a las necesidades y requerimientos de la dignidad del paciente en su totalidad y no en una parcialidad funcional deteriorada(27).

En lo referente a la realización de la sedoanalgesia en estos paciente terminales se debe diferenciar claramente, tal y como hace el Códigos de Ética y Deontología Médica vigente en España(28), entre la sedación paliativa, indicada en estos casos, y las formas de aceleración de la muerte o eutanasia que podrían darse haciendo un uso fraudulento de esta situación. La diferencia entre ambas formas de sedación se encuentra tanto en la intencionalidad del acto que se realiza como en las dosis y fármacos utilizados, a la par que en el resultado obtenido. En la sedación se busca disminuir el nivel de conciencia con la dosis necesaria de fármacos para evitar que el paciente perciba el síntoma refractario y mejorar su confort. En la eutanasia se busca deliberadamente la muerte anticipada, tras la administración de fármacos a dosis mayores de lo indicado.

¿Cómo se llevan a cabo los cuidados en el final de la vida contemplados en los protocolos de donación en asistolia controlada? En primer lugar, sería conveniente valorar los aspectos relacionados con el medio donde se produce el fallecimiento del paciente. Aunque está previsto que pueda realizarse en las propias UCIs, lo habitual, para facilitar el posterior manejo del cadáver, es que se realice en el quirófano, rodeado de personal extraño, en un ambiente de máxima tecnificación y con toda la estructura material y humana necesaria para realizar, inmediatamente después de la determinación de la muerte, la cirugía de extracción multiorgá- nica. De esta forma, y aunque se espere un posible beneficio para los receptores de los órganos y consideremos como aspecto encomiable la gratuidad y altruismo del donante, debemos cuestionarnos, aunque solo sea para valorar este acto en su justa medida, si se está ofreciendo a los pacientes una muerte verdaderamente humana. En segundo lugar, también es necesario considerar las dificultades que la administración de sedoanalgesia encierra en estos casos. La complejidad de las decisiones involucradas en la asistencia del paciente, el esfuerzo realizado para la información y consentimiento familiar o el coste material y humano en la organización de la extracción multiorgánica podrían presionar, aún involuntariamente, al médico encargado a realizar la sedación terminal con la consecuencia de un inadecuado empleo de fármacos que aceleren la muerte del paciente(29). Este conflicto de intereses, que puede desembocar en actos de eutanasia más o menos encubierta, es inseparable de las formas de donación en asistolia controlada y se fundamentan en la necesidad del cese de la función circulatoria temprana después de la extubación, junto con la dificultad para predecir con suficiente sensibilidad y certeza el tiempo restante hasta el fallecimiento(30).

De esta forma, se hace necesaria la garantía de un ambiente libre de presiones para el facultativo que asiste al donante y un estricto control de las medidas de sedación que, con arreglo a criterios clínicos y siguiendo guías validadas, atestigüen su correcta utilización. Este proceso debe constar claramente en la historia clínica del paciente, como única forma de adquirir y mantener la confianza suficiente para que estas dificultades no atenten contra la legitimidad de esta sedación.

\section{Diagnóstico de muerte tras la RTSV}

Este asunto ha constituido el eje principal en torno al juicio ético sobre la donación en asistolia. La consideración y definición de los criterios clínicos de muerte, la diferenciación entre la muerte circulatoria y la encefálica y el respeto a la Dead Donor Rule han sido objeto de un gran número opiniones enfrentadas sobre estos procedimientos, cuyo espectro en el debate ético comprende desde su consideración como formas de sofisticado e inadmisible canibalismo(31) hasta la necesidad de abolir la regla del donante muerto(32) o 
facilitar formas de donación eutanásica(33).

El respeto a la Dead Donor Rule, que determina inequivocamente el diagnóstico de muerte previo a la extracción de órganos, que impida que ésta pueda ser causa directa de la muerte del donante, se ha establecido como criterio para el desarrollo de las técnicas de trasplante en los países occidentales. Médicamente, los aspectos relacionados con el conocimiento de la muerte se refieren no tanto a la concepción de la muerte en sí como al diagnóstico cierto, que permita afirmar la presencia de esta realidad en un sujeto que yace "postrado clínicamente" (34:58). Reclama así la constatación de la muerte por parte del médico mediante un juicio diagnóstico. De este modo, resulta preciso diferenciar dicha realidad de otra distinta que corresponde al proceso de la muerte o agonía. Esta se considera como una fase final de la vida que implica la proximidad de la muerte, pero que aún no se identifica con ella, en la que persiste la individualidad del sujeto y que exige unas atenciones acordes con la dignidad del ser humano. La muerte clínica constituye el evento en el que se reconoce este nuevo estado, que compromete la dimensión ontológica del sujeto, que pasa de persona a cadáver y abre la posibilidad de actuaciones como la inhumación, la incineración o la donación de órganos. Existe también la posibilidad de considerar la muerte como un proceso continuo(35), que tendría lugar desde el establecimiento de la situación de irreversibilidad o terminalidad hasta la muerte de la última célula del organismo. Este planteamiento no es capaz de definir los criterios clínicos empleados para el diagnóstico de muerte y, aunque pueda ser objeto de discusión filosófica, no permite establecer un diagnóstico homogéneo del momento de la muerte, que tendría un carácter variable y subjetivo.

La muerte clínica es un evento diagnóstico determinado por la constatación del cese irreversible de las funciones y estructuras constitutivas de un organismo vivo humano, siendo ineludible definirla de la manera más precisa posible, reconociendo que encierra un "necesario momento de imprecisión" (34:59). La definición de muerte más aceptada internacionalmente es la desarrollada en 1982 por la President's Comission for the Study of Ethical Problems and Biomedical and Behavioral Research, que dispone la Uniform Determination of Death
Act(36), por la que se establece que "un individuo está muerto cuando le ha sobrevenido bien el cese irreversible de las funciones respiratorias y circulatorias o el cese irreversible de todas las funciones cerebrales, incluyendo el tronco cerebral, y que esta determinación de la muerte debe realizarse de acuerdo con los estándares médicos aceptados". Por tanto, en principio, se podría considerar que uno u otro criterio cabría utilizarlos dependiendo de la situación clínica en la que se encontrase el paciente. Tal es así que el cese permanente de la circulación, como criterio habitual, se utiliza en la mayoría de las comprobaciones de la muerte; mientras que el cese irreversible de las funciones encefálicas se considera cuando las funciones cardiorrespiratorias están mantenidas con medidas artificiales.

La dificultad se plantea cuando para el diagnóstico de muerte clínica, por criterios circulatorios, se asocia un elemento que puede alterar la evolución natural de la parada cardiocirculatoria hacia la pérdida completa de la actividad cerebral. Este hecho se produce en los protocolos de donación en asistolia controlada, en los que la necesidad de una extracción rápida de los órganos podría llevarse a cabo aun cuando el cese de la actividad cerebral pueda no ser total y cuando el paciente no alcance a cumplir los criterios de muerte encefálica. En este caso, podría sugerirse que el explante se realiza sobre un paciente aún no en situación de muerte clínica, violando de esta manera la Dead Donor Rule. Por lo tanto, el problema adquiere dos nuevas dimensiones: definir si el cese de las funciones circulatorias es irreversible y calcular cuánto tiempo es necesario para garantizar la muerte encefálica, respetando así la Dead Donor Rule.

Si consideramos por irreversible la incapacidad de restablecer la función circulatoria mediante cualquier medio (maniobras de reanimación o dispositivos de asistencia que reactiven la función circulatoria, por ejemplo), no podríamos considerar que estos pacientes cumplen los requerimientos para ser considerados como fallecidos. Por este motivo, se sugirió hace algunos ańos la distinción entre el cese irreversible y el cese permanente de las funciones vitales(37). Este último correspondería a la forma habitual de diagnóstico clínico consistente en la pérdida de la función cardiorres- 
piratoria, la cual no se espera que regrese, ni de forma espontánea ni por medio de maniobras de reanimación, porque estas no van a ser insaturadas. El cese permanente constituiría así un marcador temprano del estado de irreversibilidad y podría considerarse como válido igualmente para determinar el diagnóstico de fallecimiento. En lo referente al tiempo necesario para considerar la imposibilidad de recuperación espontánea, no se han encontrado casos en los que el restablecimiento de las funciones cardiovasculares se haya producido espontáneamente después de más de 65 segundos de parada cardiorrespiratoria, siempre que no se haya instaurado maniobras de resucitación (38-40); sin embargo, esta conclusión también ha sido cuestionada por otros autores(41). En definitiva, no existe consenso internacional inequívoco sobre el tiempo mínimo necesario para la constatación del cese permanente de las funciones circulatorias, oscilando según los distintos países entre dos, cinco, diez o veinte minutos(42).

El segundo problema es el establecimiento del tiempo necesario para la constatación de la muerte encefálica, después del cese irreversible - permanente en nuestro caso- de la función circulatoria. Los autores que defienden la compatibilidad de esta forma de donación con la Dead Donor Rule argumentan que, una vez que el cese de la función circulatoria se haya producido de forma permanente, el daño y la destrucción cerebral ocurrirán tanto si los órganos están presentes como si han sido extraídos; por lo tanto, no se incumpliría la norma. Esta disposición, recogida en las distintas conferencias de consenso y en varios protocolos, ha sido ampliamente cuestionada desde otras posturas que consideran este argumento como construido de forma artificial y forzada, afirmando que si en el momento del explante no se cumplen los criterios de muerte cerebral - hecho poco probable en los protocolos con tiempos de observación cortos- no se puede considerar como cierta la muerte clínica del donante y estaríamos ante un incumplimiento de la Dead Donor Rule(43). A partir de esta afirmación se podría considerar que estas formas de donación resultarían éticamente rechazables(44), o bien admisibles, considerando únicamente los criterios circulatorios como criterios de muerte clínica(45) o replanteando la utilidad de la Dead Donor Rule como imperativo bioético de los procesos de donación(46). Algunos autores, avanzando en este argumento, establecen el momento del diagnóstico de situación irreversible de la enfermedad como el punto de no retorno, a partir del cual podríamos considerar la donación o la posibilidad de realizar donaciones eutanásicas en pacientes con enfermedades terminales(47-48).

\section{Discusión}

Si consideramos, por una parte, los procesos de donación y trasplante de órganos en los países occidentales como reflejo de los fines propios de la medicina, produciendo un bien objetivo al receptor, a la comunidad y, en cierto sentido, también al donante, y, por otra, la RTSV extraordinaria como forma de evitar la obstinación terapéutica en pacientes extremadamente graves, en la cual que las medidas resultan desproporcionadas para el paciente o enormemente gravosas para la sociedad, nos deberíamos plantear la pregunta de si es posible, siempre que no exista oposición expresa, la asociación de estas dos realidades en beneficio de una distribución de recursos más eficiente y una mejora de la salud en la población. La respuesta, aparentemente sencilla, resultaría casi evidente en un primer momento. Dicha contestación se complica al profundizar sobre las decisiones y comportamientos relacionados con las actuaciones que esta asociación comporta. En este trabajo se han analizado, sistemáticamente, cinco de los motivos que podrían afectar a la validez de la pregunta inicial.

En primer lugar, la dificultad para realizar un diagnóstico certero de la situación clínica del donante y de su pronóstico, los obstáculos que se pueden presentar en una adecuada realización de la retirada de las medidas invasivas de soporte vital y la obligatoriedad de considerar periodos de tiempo cortos que permitan la validez de los órganos en beneficio del receptor, junto con la necesidad de instaurar medidas no beneficiosas y en algunos casos perjudiciales para el donante aún con vida, constatan la existencia, en la práctica, de un verdadero conflicto de intereses entre donante y receptor. En segundo término, la forma y el tiempo en el que se determina el momento del fallecimiento también se ha visto que no está exento de debate y parece que el diagnóstico de muerte 
clínica, una vez aceptados los criterios de muerte encefálica por la comunidad científica, vuelve a ponerse en tela de juicio. Este hecho pone en duda la utilidad de uno de los pilares fundamentales de los sistemas de donación: la Dead Donor Rule, la cual podría no estar respetándose en estos pacientes. Por ello, se ha llegado a plantear abogar por su supresión directa y la adopción de otras formas de consenso en lo referente a la donación de órganos.

Todas estas dificultades plantean un itinerario complicado de llevar a cabo, tal y como actualmente lo plantean los distintos protocolos de donación en asistolia. Existe riesgo de menoscabar la dignidad del paciente agonizante si es empleado como un mero instrumento al servicio de otros intereses, por muy elogiables que estos puedan ser, disminuyendo en la práctica el valor intrínseco de la persona. Junto con este aspecto, la posibilidad de inercia, ambición, error o negligencia podría llevarnos en la práctica a una aplicación poco cuidadosa de estos protocolos, perjudicando así a donantes y a receptores. Desde una perspectiva ética consecuencialista, estas objeciones quizá no sean valoradas debidamente.

También se podría dudar sobre si la donación en asistolia controlada contribuirá a constituir un beneficio para la sociedad o si, por el contrario, favorecería un camino plagado de "pendientes resbaladizas", que podrían perjudicar al donante, al receptor, al sistema de organización de trasplantes y a la propia sociedad. Una inadecuada aplicación de estos protocolos podría determinar un efecto paradójico y contrario al buscado: la disminución de la tasa de donación por una pérdida de confianza en el programa de donaciones, en el diagnóstico cierto del fallecimiento del donantes o en el planteamiento de la RTSV de un paciente crítico. Por tanto, solamente una ética del trasplante pública, sincera, controlada, expuesta a la revisión y basada en el beneficio no contrapuesto del donante y del receptor, que considere al donante como provisto de la máxima dignidad, indisponibilidad e inviolabilidad, y que adopte la norma personalista en beneficio del donante y receptor en sustitución del principio de utilidad, dará los frutos que hasta ahora ha conseguido. Tal vez una involucración mayor de los comités asistenciales de bioética, al igual que en las formas de trasplan- te en vivo, puedan jugar un buen papel de control y garante de la calidad. Por consiguiente, a la pregunta que se planteaba al principio debemos responder con una enorme cautela: los donantes en asistolia controlada pueden no ser, desde el punto de vista ético, el camino adecuado para el correcto desarrollo de un programa de trasplantes ejemplar, en muchos aspectos, como es el español.

\section{Conclusiones}

No resulta sencillo concluir, sobre si este modo de donación respeta, de forma plena, el comportamiento ético que la actividad médico-asistencial en materia de trasplantes reclama. A lo largo de este trabajo se han descrito, analizado y valorado argumentos favorables a su introducción, sin embargo, también se han expuesto razones, impedimentos e interrogantes que permitirían vacilar sobre su aceptación sin ningún tipo de reservas. De esta forma se podría concluir:

La donación multiorgánica según los protocolos tipo III constituye un modo particular de donación. No comparte algunas de sus características propias con otras formas de donación y, por lo tanto, no son equiparables a las realizadas hasta este momento en nuestro país. El factor determinante es la consideración del futuro donante, que necesita planificación y actuaciones propias mientras permanece con vida, y el modo de determinar el momento exacto de su muerte.

El respeto al principio de autonomía de los donantes podría verse afectado, al no cumplirse algunos de los elementos necesarios para una información óptima que garantice una decisión libre por parte del donante o sus representantes.

La toma de medidas invasivas y no terapéuticas, contrarias al beneficio del donante, debe ser considerada como una instrumentalización de este, con fines distintos de su propio bien, y que podrían considerarse contrarias a las disposiciones de algunos convenios internacionales en materia de derechos humanos.

La realización de la RTSV y sedoanalgesia resultan igualmente complicadas por el posible conflicto de intereses entre donante y donación. Las medidas realizadas de este modo deben quedar 
fielmente reflejadas y finamente reguladas para evitar formas de aceleración de la muerte.

Es imprescindible mantener la vigencia y el respeto a la Dead Donor Rule, como elemento constitutivo esencial de los programas de trasplante, para que constituyan un verdadero elemento de confianza y cohesión social.

Es preciso clarificar y ampliar el consenso, aumentando la investigación y la reflexión interdisciplinar existente en lo referente a los criterios de determinación clínica de la muerte. Existen notables diferencias entre los distintos protocolos, en la consideración del tiempo necesario para determinar irreversible el cese de la función circulatoria y encefálica. Esta circunstancia podría fomentar la duda y el arbitrio a la hora de alcanzar una certeza completa sobre el fallecimiento del donante.

Por todos estos motivos, los programas de donación en asistolia controlada, tal y como están actualmente confeccionados, plantean difíciles problemas e inconvenientes éticos que harían prudente una respuesta negativa a su instauración y generalización. Asimismo, sería preciso contar con mecanismos de control que determinasen una correcta indicación y un procedimiento que respete, de forma prioritaria, la dignidad y protección del donante, una vez decidida su puesta en funcionamiento. 
Análisis de los aspectos bioéticos en los programas de donación en asistolia controlada - José M. Álvarez, José A. Santos

\section{Referencias}

1. Manara AR, Murphy PG, O'Callaghan G. Donation after Circulatory Death. British Journal of Anaesthesia 2012; 108 : 108-121.

2. Observatorio global de Donación y Trasplante. Disponible en: http://www.transplant-observatory.org/pages/ home.aspx (consultado el 10 de diciembre de 2012).

3. A Definition of Irreversible Coma. Report of the Ad Hoc Committee of the Harvard Medical School to Examine the Definition of Brain Death. The Journal of the American Medical Association 1968; 205: 337-340.

4. Orr RD, Gundry SR, Bailey LL. Reanimation: Overcoming Objections and Obstacles to Organ Retrieval from NonHeart-Beating Cadaver Donors. Journal of Medical Ethics 1997; 23: 7-11;

5. Nijkamp D, van der Bij W, Verschuuren EA, et al. Non-Heart-beating Lung Donation: How Big is the Pool? The Journal of Heart and Lung Transplantation 2008; 27(9): 1040-1042.

6. Boucek M, Mashburn C, Dunn SM, et al. Pediatric Heart Transplantation after Declaration of Cardiocirculatory Death. The New England Journal of Medicine 2008; 359: 709-714.

7. Koostra G, Daemen JHC, Ooman APA. Categories of Non-Heart-Beating Donors. Transplantation Proceedings 1995; 27(5): 2893-2894.

8. University of Pittsburgh Medical Center Policy and Procedure Manual. Kennedy Institute of Ethics Journal 1993; 3: A1-A15.

9. Robertson JA. The Dead Donor Rule. The Hastings Center Report 1999; 29: 6-14.

10. Bernat JL, D’Alessandro AM, Port FK, et al. Report of a National Conference on Donation after Cardiac Death. American Journal of Transplantation 2006; 6: 281-291.

11. Dominguez-Gil B, Haase-Kromwijk B, Van Leiden H, et al. Current Situation of Donation after Circulatory Death in European Countries. Transplant International 2011; 24: 676-86.

12. Iceta M. El concepto médico de futilidad y su aplicación clínica. Pamplona: tesis doctoral de la Universidad de Navarra; 1995. Disponible en: http://www.unav.es/humbiomedicas/gherranz/pagina_4.html (consultado el 10 de diciembre de 2012).

13. Manno EM, Wijdicks EF. The Declaration of Death and the Withdrawal of Care in the Neurologic Patient. Neurologic Clinics 2006; 24: 159-169.

14. Beauchamp TL, Childress JF. Principles of Biomedical Ethics. 5a ed. New York: Oxford University Press; 2001.

15. Pellegrino E, Thomasma D. For the Patient's Good. The Restoration of Beneficence in Health Care. New York: Oxford University Press; 1988: 48-205.

16. Kant I. Grundlegung zur Metaphysik der Sitten (1785). Reimpresión de la 3a ed. Hamburg: Meiner; 1965.

17. Convenio Europeo sobre los Derechos Humanos y la Biomedicina, Art. 6.1., 1997.

18. Zeiler K, Furberg E, Tufveson G, et al. The Ethics of Non-Heart-Beating Donation: How New Technology Can Change the Ethical Landscape. Journal of Medical Ethics 2008; 34 (7): 526-29.

19. Schnitzler M, Whiting JF, Brennan DC, et al. The Life-Years Saved by a Deceased Organ Donor. American Journal of Transplantation 2005; 5: 2289-229.

20. Doig CJ, Rocker G. Retrieving Organs from Non-Heart-Beating Organ Donors: A Review of Medical and Ethical Issues. Canadian Journal of Anesthesia 2003; 50(10): 1069-76.

21. Childress JF. Non-Heart-Beating Donors of Organs: Are the Distinctions Between Direct and Indirect Effects \& Between Killing and Letting Die Relevant and Helpful? Kennedy Institute of Ethics Journal 1993; 3(2): 203-16.

22. Steinberg D. The Antemorten Use of Heparin in Non-Heart-Beating Organ Transplantation: A Justification Based on the Paradigm of Altruism. Journal of Clinical Ethics 2003; 14: 18-25.

23. Sgreccia E. Manual de Bioética, tomo I. Fundamentos y ética biomédica. Madrid: Biblioteca de Autores Cristianos; 2009.

24. Tomás y Garrido GM, Postigo E. Bioética personalista: ciencia y controversias. Madrid: Ediciones Internacionales Universitarias: 2007.

25. Gardiner D, Sparrow R. Not Dead Yet: Controlled Non-Heart-Beating Organ Donation, Consent, and the dead Donor Rule. Cambridge Quarterly of Healthcare Ethics 2010; 19: 17-26.

26. Truog, RD, Campbell ML, Curtis JR, et al. Recommendations for End-of-Life Care in the Intensive Care Unit: A Consensus Statement by the American College of Critical Care Medicine. Critical Care Medicine 2008; 36(3): $953-963$.

27. García Sánchez E. El rescate de lo humano en el enfermo que se muere. Cuadernos de Bioética 2012; 23(77): $135-49$.

28. Código de Ética y Deontología Médica. Espańa. 2011. Cap. VII, art. 36. 
29. Vincent JL y Brimioulle S. Non-Heart-Beating Donation: Ethical Aspects. Transplantation Proceedings 2009; $41: 576$ 78.

30. Wind J, Snoeijs MG, Brugman CA, et al. Prediction of Time of Death after Withdrawal of Life-Sustaining Treatment in Potential Donors after Cardiac Death. Critical Care Medicine 2012; 40(3): 766-69.

31. Fox RC. An Ignoble Form of Cannibalism: Reflections on the Pittsburgh Protocol for Procuring Organs from NonHeart-Beating Cadavers. Kennedy Institute of Ethics Journal 1993; 3(2): 231-239.

32. Halpern SD, Troug RD. Organ Donors after Circulatory Determination of Death: Not Necessarily Dead, and It Does Not Necessarily Matter. Critical Care Medicine 2010; 38(3): 1011-12.

33. Wilkinson D, Savulescu J. Should We Allow Organ Donation Euthanasia? Alternatives for Maximizing the Number and Quality of Organs Transplantation. Bioethics 2012; 26(1): 32-48.

34. Trueba, JL. La muerte clínica: un diagnóstico y un testimonio. Anales del Sistema Sanitario de Navarra 2007; 30(3): 57-70.

35. Khushf G. A Matter of Respect: A Defense of the Dead Donor Rule and of a "Whole-Brain" Criterion for Determination of Death. Journal of Medicine and Philosophy 2010; 35: 330-64.

36. Guidelines for the Determination of Death. Report of the Medical Consultants on the Diagnosis of Death to the President's Commission for the Study of Ethical Problems in Medicine and Biomedical and Behavioral Research. Journal of the American Medical Association 1981; 246(19): 2184-2186.

37. Bernat JL. How the Distinction Between "Irreversible" and "Permanent" Illuminates Circulatory-Respiratory Death Determination. Journal of Medicine and Philosophy 2010; 35: 242-255.

38. Bray JG Jr. The Lazarus Phenomenon Revisited. Anesthesiology 1993; 78(5): 991.

39. Maleck WH, Piper SN, Triem J, et al. Unexpected Return of Spontaneous Circulation after Cessation of Resuscitation (Lazarus Phenomenon). Resuscitation 1998; 39: 125-28.

40. Hornby K, Hornby L, Shemie SD. A Systematic Review of Autoresuscitation after Cardiac Arrest. Critical Care Medicine 2010; 38(5): 1246-53.

41. Rady MY, Verheijde JL. Lazarus Phenomenon, Autoresuscitation, and Nonheart-Beating Organ Donation. Critical Care Medicine 2010; 38(8): 1757-58.

42. Dhanani S, Hornby L, Ward R, et al. Variability in the Determination of Death after Cardiac Arrest: A Review of Guidelines and Statements. Journal of Intensive Care Medicine 2012; 27(4): 238-252.

43. Verheijde JL, Rady MY, McGregor, Joan. Recovery of Transplantable Organs after Cardiac or Circulatory Death: Transforming the Paradigm for the Ethics of Organ Donation. Philosophy, Ethics, and Humanities in Medicine 2007; $2: 8$.

44. Rady MY, Verheijde JL, McGregor J: Organ Donation after Circulatory Death: The Forgotten Donor? Critical Care Medicine 2006; 10: 166.

45. Kerridge IH, Saul P, Lowe M, et al. Death, Dying and Donation: Organ Transplantation and the Diagnosis of Death $J$ Med Ethics 2002; 28(2): 89-94.

46. Truog, RD, Miller FG. The Dead Donor Rule and Organ Transplantation. The New England Journal of Medicine 2008; 359: 674-675.

47. Zamperetti, N. Defining Death in Non-Heart Beating Organ Donors. Journal of Medical Ethics 2003; 29: 182-185.

48. Wilkinson D, Savulescu J. Should We Allow Organ Donation Euthanasia? Alternatives for Maximizing the Number and Quality of Organs Transplantation. Bioethics 2012; 26(1): 32-48.

Recibido: 11 de diciembre de 2012

Aceptado: 15 de febrero de 2013 